Case Report

\title{
Sudden death associated with melanoma brain metastases
}

\author{
Durão H. Carlos ${ }^{1,2}$, Veiga G. Marcos ${ }^{1}$, Nina Pedro², Gonçalves M. \\ Manuela $^{2}$, Pedrosa Frederico ${ }^{2}$ \\ ${ }^{1}$ Hospital Vila Franca de Xira, Lisbon, Portugal \\ ${ }^{2}$ National Institute of Legal Medicine and Forensic Sciences - Lisbon, Portugal
}

\section{Keywords: \\ Brain; \\ Melanoma; \\ Metastasis}

\begin{abstract}
A 48-year-old male Caucasian, with no relevant medical history except for a mild depression, was found by the partner, passed out on the bedroom floor. Since he was found in cardiac arrest, cardiopulmonary resuscitation was attempted, without success. Initially, it was suspected to be a suicide attempt and autopsy findings revealed coronary atherosclerosis of about $40 \%$, with no other recoverable cardiac findings.

The brain showed multiple probable neoplastic lesions, associated with cerebral and cerebellar hemorrhage. The primary tumor was not identified, but the victim had multiple cutaneous nevi. Histological examination revealed melanoma metastases, confirmed by immunohistochemistry.

In this case, the forensic autopsy allowed an accurate determination of the cause of death. Besides having fulfilled its role to the judiciary system, the autopsy also had relevance from an epidemiological point of view, which is essential for Public Health prevention programs.
\end{abstract}

\section{Correspondence:}

Carlos Durão: Forensic Medical Expert

Hospital Vila Franca Xira - Estrada Nacional $n^{\circ} 1$, Povos

2600-009 Vila Franca de Xira - Lisboa - Portugal.

ORCID ID: 0000-0003-4799-4842

Email:drcarlosdurao@hotmail.com

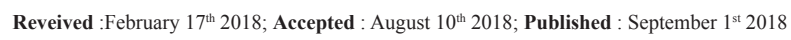

Citation : Carlos DH, Marcos VG, Pedro N, Manuela GM, Frederico P.. Sudden death associated with melanoma brain metastases. J Pathol Nep 2018;8: 1412-15. DOI: 10.3126/jpn.v\%vi\%i.20896

Copyright: This is an open-access article distributed under the terms of the Creative Commons Attribution 4.0 International License, which permits unrestricted use, distribution, and reproduction in any medium, provided the original author and source are credited.

\section{INTRODUCTION}

Brain metastases usually occur at advanced stages of cancer. However, brain metastases can be the first and only clinical manifestation of an unknown tumor. ${ }^{1,2}$ It is estimated that $20 \%$ to $25 \%$ of cancer patients develop brain metastases and autopsy studies demonstrate that up to $25 \%$ of patients die from it. ${ }^{1,3,4}$ A study shows that 3 to $14 \%$ of all intracranial metastases will eventually bleed. ${ }^{5}$

Intracranial metastases can be located in the parenchyma (cerebral hemispheres, cerebellum, brainstem) or the meninges. Brain metastases are responsible for $2 / 3$ of intracranial metastases, and may be solitary or multiple. 

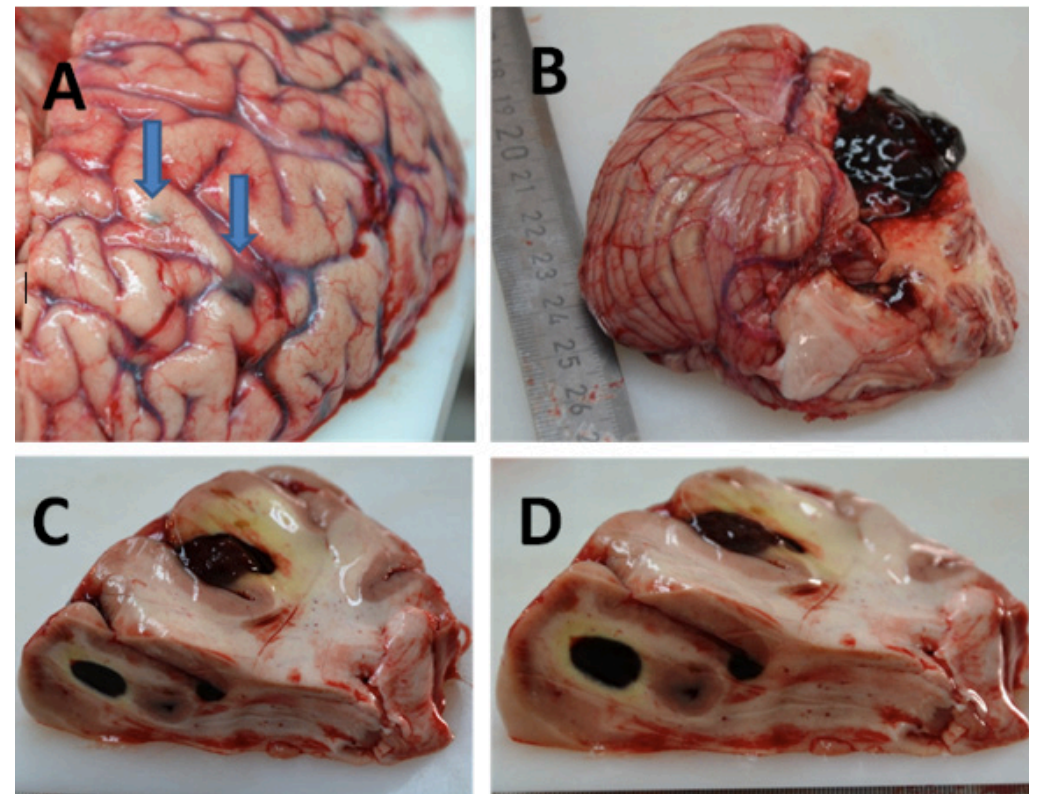

Figure 2 (A-D): Brain aspect. Observable macroscopic cerebral hemorrhage, which is more often related to malignant melanoma metastases than to CNS primary tumors. Note the dark coloured nodules at the surface (arrowhead) (A)

Some tumors, like melanoma, generally produce multiple metastases, while others, like breast carcinoma, arise most often with a single lesion. ${ }^{4,6}$

Malignant melanoma is the third most common cause of central nervous system (CNS) metastases, after breast and lung cancer, although it has the highest propensity to metastasize to that location. ${ }^{7}$ Unlike lung, kidney and breast cancer metastases, that are predominantly solitary, the malignant melanoma often metastasizes to multiple locations. $^{8}$

The 5-year cumulative risk for developing melanoma CNS metastases is approximately 7 percent. $^{9}$ In patients with malignant melanoma, the intracranial metastases appear to occur in $58 \%$ of male gender and $42 \%$ of female. ${ }^{10}$ However, autopsy reports indicate that the incidence of brain metastases may be as high as $75 \%$ post-mortem, being most of them clinically silent. ${ }^{11}$

Melanoma patients with brain metastases in general have a poor prognosis. In a combined analysis of two series totaling almost 1400 patients, the median survival was four months, and one year survival rates were 9 and $19 \%$, respectively. ${ }^{12}$ In this context, it is relevant to state that 20 to $54 \%$ of melanoma patients die from brain metastasesrelated complications. ${ }^{13}$

\section{CASE REPORT}

A 48-year-old male Caucasian, with no relevant medical history except for a mild depression, was found by the partner, passed out on the bedroom floor. Since he was found in cardiac arrest, cardiopulmonary resuscitation was attempted, without success. Initially, it was suspected to be a suicide attempt and autopsy findings revealed coronary atherosclerosis of about $40 \%$, with no other recoverable cardiac findings.

The brain showed multiple probable neoplastic lesions, associated with cerebral and cerebellar hemorrhage. (fig. 1A-D) The primary tumor was not identified, but the victim had multiple cutaneous nevi. Histological examination revealed melanoma metastases, (fig.2A\&B) confirmed by immunohistochemistry (fig.3), which led to the conclusion that the case was of melanoma metastases.

\section{DISCUSSION}

Malignant melanoma is a relatively common, usually asymptomatic tumor. Although most melanomas have its origin on skin, other places of origin include oral, anal and genital mucosa, esophagus, eye and meninges. Like other epithelial malignancies of the skin, sunlight may play an important role in the development of malignant melanoma, but it's not the only etiological factor. The presence of a pre-existing nevus, hereditary factors and exposure to carcinogens may trigger disease development. ${ }^{8}$ Approximately $80 \%$ of brain metastases are located in the cerebral hemispheres, $15 \%$ in the cerebellum and $5 \%$ in the brain stem. ${ }^{14}$ There is an association between the size of malignant melanoma brain metastases and the respective clinical signs. When symptoms occur, they are nonspecific and vary depending on the location of the lesion. Headache 

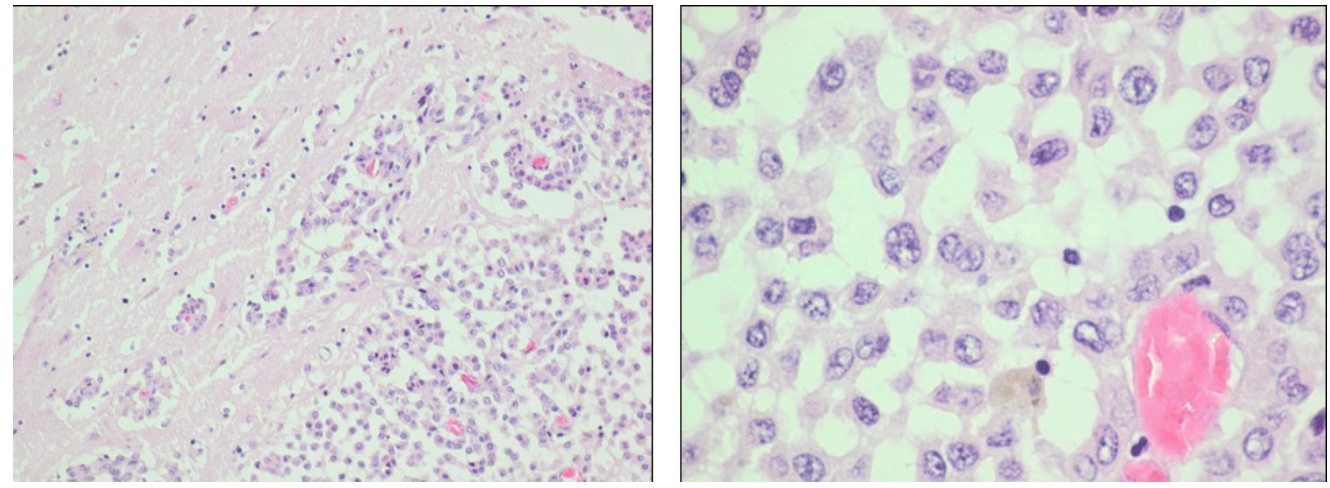

Figure 2A: Proliferation of neoplastic cells, characterized by cells with marked atypia and pleomorphism and is richly vascularized. In the center of the field there is a cell containing a small amount of melanin pigment. (HE stain; X50) B. Bizarre nuclei, vacuoles, pleomorphic cells, a blood vessel in cerebellum (HE stain; X100).

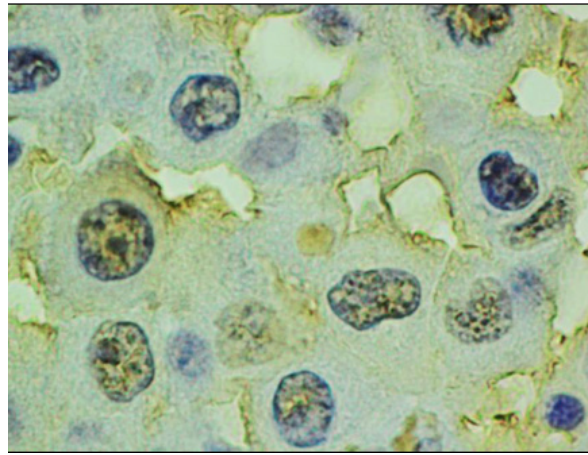

Figure 3: Immunostaining of neoplastic cells was positive for $S 100$ protein (IHC; X400)

is the most common presenting symptom, but patients may also present more serious symptoms like seizures, hemiplegia or visual compromise, due to raised intracranial pressure. These phenomena may suggest large $(>4 \mathrm{~cm})$ lesions. ${ }^{8}$

Five to ten percent of brain metastases present acutely due to stroke. This may be caused by hemorrhage into a metastases, hypercoagulability, invasion or compression of an artery by tumor, or embolization of tumor cells. ${ }^{15}$ Unlike most other cancer metastases to the brain, melanoma has a high propensity to hemorrhage spontaneously, with rates ranging from 8.6 to 24 percent. ${ }^{16}$ This can be the first and only symptom of a metastasized neoplastic disease, as was proved to be this case.

\section{CONCLUSION}

In this case, the forensic autopsy allowed an accurate determination of the cause of death. Besides having fulfilled its role to the judiciary system, the autopsy also had relevance from an epidemiological point of view, which is essential for Public Health prevention programs.
Currently, given the greater information available on the first signs of cutaneous melanoma, many cases can be cured surgically. Awareness and screening programs have a crucial role in reducing deaths from melanoma.

\section{Conflict of Interest: None}

\section{REFERENCES}

1. Patchell AR. Metastatic brain tumors. In: Brain tumors in adults. Black PM, Wen PY (eds.). WB Saunnders Company, Philadelphia,1995. pp95-9. Crossref

2. Nguyen LN, Maor MH, Oswald MJ. Brain metastases as the only manifestation of an undetecd primary tumor. Cancer 1998;83:21814. $\underline{\text { Crossref }}$

3. Thapar K, Laws ER. Tumores Del Sistema Nervioso Central. In Oncologia Clínica. Murphy GP, Lawrence W (eds.). American Cancer Society, Washington, 1995. pp.424-62.

4. A.J.Santos et al. Metástases cerebrais. Rev. Neurociências 2001;9:206.

5. Mandybur TI. Intracranial hemorrhage caused by metastatic tumors Neurology. 1977;27:650-5. Crossref

6. Posner JB. Intracranial metastases. In: Neurologic complications of cancer. Posner JB (ed.). FA Davis Company, Philadelphia, 1995 pp.77-110.

7. Barnholtz-Sloan JS, Sloan AE, Davis FG, Vigneau FD, Lai P, Sawaya RE. Incidence proportions of brain metastases in patients diagnosed (1973 to 2001) in the Metropolitan Detroit Cancer Surveillance System. J. Clin. Oncol 2004;22:2865-72.

8. Goulart CR, Mattei TA, Ramina R. Cerebral melanoma metastases: a critical review on diagnostic methods and therapeutic options. ISRN Surg. 2011, 276908. Crossref

9. Gottschalk J, Döpel SH, Schulz J, Fuchs M, Martin H. Significance of immunohistochemistry in neuro-oncology. V. Keratin as a marker for epithelial differentiation of primary and secondary intracranial and intraspinal tumors. Zentralblatt fur Allgemeine Pathologie und Pathologische Anatomie 1987;133:133-45. Crossref

10. Saha S, Meyer M, Krementz ET, et al. Prognostic evaluation of intracranial metastases in malignant melanoma. Annals of Surgical Oncology. 1994;1:38-44. Crossref 
11. Shapiro DG, Samlowski WE. Management of melanoma brain metastases in the era of targeted therapy. J. Skin Cancer 2011, 845863. Crossref

12. Fife KM, Colman MH, Stevens GN, et al. Determinants of outcome in melanoma patients with cerebral metastases. J Clin Oncol 2004;22:1293. Crossref

13. Othus M, Moon J, Margolin K. Melanoma's deadly march to the brain: by what route, and can it be stopped? Cancer 2011;117:1560. $\underline{\text { Crossref }}$
14. Delattre JY, Krol G, Thaler HT, Posner JB. Distribuiton of Brain Metastases. Arch Neurol 1988;45:741-4. $\underline{\text { Crossref }}$

15. Nutt SH, Patchell RA. Intracranial hemorrhage associated with primary and secondary tumors. Neurosurg Clin N Am 1992;3:591. Crossref

16. Flanigan JC, Jilaveanu LB, Chiang VL, Kluger HM. Advances in therapy for melanoma brain metastases. Clin Dermatol 2013;1:26481. $\underline{\text { Crossref }}$ 